\title{
REESTRUTURAÇÃO PRODUTIVA E TRANSFORMAÇÕES ECONÔMICAS Região Metropolitana de São Paulo
}

\author{
Maria de Fátima Infante Araujo \\ Gerente de Base de Dados e Produção de Indicadores da Fundação Seade
}

\begin{abstract}
Resumo: Este artigo aborda os impactos da reestruturação produtiva na Região Metropolitana de São Paulo no final do século XX. Derivadas de determinações econômicas, as transformações na base técnica de produção, ao longo da década de 90, acarretaram alterações estruturais na indústria e nos serviços, bem como na estrutura ocupacional. A convergência entre a reestruturação produtiva e a concentração regional da produção industrial na RMSP, os processos inovadores e a ruptura entre as trajetórias da produção e do emprego na evolução da economia metropolitana são enfatizados neste texto.

Palavras-chave: reestruturação produtiva; Região Metropolitana de São Paulo; economia regional.
\end{abstract}

$\mathrm{C}$

om o propósito de tecer algumas considerações acerca das implicações derivadas dos impactos da reestruturação produtiva sobre a Região Metropolitana de São Paulo no final do século XX, o artigo procura relacionar dois desenvolvimentos distintos, mas profundamente inter-relacionados: as transformações na estrutura produtiva e as mudanças na estrutura ocupacional na RMSP, no transcurso da década de 90. São apresentadas algumas implicações que se mostraram cruciais para o desenvolvimento futuro da RMSP e que são derivadas dos impactos territoriais dessas transformações.

Amplamente discutido no estudo Impactos da reestruturação produtiva sobre a Região Metropolitana de São Paulo no final do século XX (Araujo, 2001), o tema está demonstrado empiricamente por meio da articulação analítica inédita entre algumas bases de dados: são trabalhadas as informações de Contas Regionais do IBGE, na série 1985-97; da Pesquisa Industrial Anual - PIA de 1996 e seu encadeamento metodológico com o Censo Industrial de 1985, também do IBGE; da série 1992-98 da Pesquisa Nacional de Domicílios - PNAD/IBGE, em tabulações especiais realizadas pelo Projeto Rurbano do Instituto de Economia da Unicamp; da série 1988-99 da Pesquisa Emprego Desemprego - PED/Seade-Dieese; e, finalmente, da Pesquisa da Atividade Econômica Paulista de 1996 - Paep/Seade.
Este artigo apresenta aspectos contidos no referido estudo, tratando-se portanto, de uma abordagem geral do tema analisado detalhadamente nos capítulos que discutem os determinantes histórico-estruturais da metropolização, a formação da RMSP, a reestruturação produtiva, a nova dinâmica da economia metropolitana nos anos 90 - em que são identificadas as principais transformações na estrutura produtiva metropolitana - e as transformações da estrutura ocupacional, bem como em suas conclusões, em que é feita uma síntese dos impactos da reestruturação produtiva sobre a RMSP, mostrando sua abrangência econômica/social/espacial, assim como algumas possíveis implicações desses processos para o desenvolvimento futuro da região.

A Região Metropolitana vem se inserindo de forma privilegiada na cadeia dos fluxos internacionais, financeiros, produtivos e culturais. Topo da rede urbana brasilei$\mathrm{ra},{ }^{1}$ detentora de uma grande, concentrada, complexa e diversificada estrutura produtiva, a região passa por processos de terciarização de sua economia, com expressivo crescimento dos serviços especializados de apoio à produção.

A RMSP, predominantemente industrial na década de 70 , constituiu a base e o cenário da crise dos anos 80 e da reestruturação tecnoprodutiva da década de 90 - quando foram geradas intensas transformações estruturais. Mudanças inter e intra-setoriais nas estruturas de produção e 
ocupacional, associadas a alterações na base técnica da produção industrial, colocaram em marcha um novo processo de reestruturação da região.

Retomando alguns aspectos da recente formação da RMSP, tratados amplamente na literatura referente ao tema, ${ }^{2}$ pode-se dizer que a RMSP, herdeira e caudatária do processo de industrialização brasileiro, realizou, em vinte anos de consolidação da industrialização (19601980), a principal transformação estrutural nos marcos do paradigma fordista da produção industrial capitalista. Alterações profundas nos processos de trabalho e nas dinâmicas socioculturais ocorreram no país e, em particular, na Região Metropolitana nesse período, o que assegurou sua predominância industrial e aprofundou sua função de pólo central da economia nacional. O alto grau de concentração da produção industrial na RMSP potencializou processos históricos de convergência dos fluxos migratórios para esta região, transformando-a na mais importante área metropolitana da América Latina. Como resultado do aumento substancial do emprego industrial e dos altos índices de crescimento econômico da década de 70, formouse, nesta região, uma vasta classe média que desenvolveu novos padrões culturais e hábitos de consumo, difundindo-se rapidamente para o restante do país.

O emprego industrial e a renda urbana gerada no período criaram inúmeras atividades econômicas e novas ocupações de natureza urbana, fundamentais para a formação do enorme mercado de consumo e de trabalho da RMSP.

Em meio à ditadura militar e diante das conseqüências da crise no padrão de financiamento internacional, no final dos anos 70, interrompeu-se esse ciclo de crescimento e teve início um longo período de estagnação da economia metropolitana. Abriu-se, então, durante a década de 80 , um período de sérias dificuldades para a economia brasileira, quando alternaram-se conjunturas de recessão e crise, com exceção dos poucos anos de crescimento sob a influência do Plano Cruzado. O árduo processo de redemocratização da sociedade brasileira conviveu com uma penosa agenda econômica e social.

A RMSP, centro da produção industrial e também centro político de organização dos diversos atores sociais trabalhadores, empresários, intelectuais e políticos -, sofreu de forma mais aguda os efeitos da crise - de financiamento do setor público e da produção industrial -, com graves conseqüências ao seu desenvolvimento futuro. Contudo, durante esses anos, gestaram-se profundas transformações estruturais no aparato produtivo e no mercado de trabalho que se realizaram na década de 90 .
No plano internacional, nos anos 70 e 80 , as mudanças no sistema de produção fordista, principalmente nos Estados Unidos e na Europa, passaram a ter repercussões profundas no desenvolvimento das principais regiões metropolitanas. Segundo Scott (1992), transformações significativas ocorreram na estrutura interna das grandes cidades e uma vigorosa reestruturação da geografia global da urbanização pôs-se em marcha, em resposta às novas tendências econômicas. As grandes cidades do capitalismo moderno continuaram a crescer e a concentrar novas atividades, pois os elementos que levaram algumas atividades à descentralização tenderam a intensificar a divisão social do trabalho e a renovar as atividades econômicas das aglomerações metropolitanas em outros setores, como, por exemplo, no setor financeiro.

No Brasil, o surgimento e o florescimento dos setores de produção flexível e a internacionalização maciça decorrente do capitalismo moderno produziram impactos na reestruturação tecnológica da RMSP que foram sentidos, com maior intensidade, somente na década de 90.

A RMSP surge como ponta de lança das mudanças estruturais da economia brasileira ao se transformar, nos anos 90, no principal centro terciário do país. A concentração do sistema bancário na região potencializou e induziu a criação e o desenvolvimento de novas atividades de serviços - principalmente ligadas às tecnologias de informação e à gestão dos negócios empresariais e financeiros.

A reestruturação tecnológica e as transformações estruturais aprofundaram-se no sentido da constituição de uma metrópole de serviços - e de serviços produtivos que tenderão, em última instância, a definir o caráter que poderá assumir o seu desenvolvimento regional, visto que tais transformações produziram impactos com inúmeras implicações - essenciais para a definição de ações estratégicas de desenvolvimento de longo prazo para o conjunto da região.

$\mathrm{Na}$ verdade, a reestruturação produtiva em curso no país, acelerada a partir dos anos 90, longe de esvaziar a Região Metropolitana como centro industrial, agregou-lhe o papel de principal centro financeiro e de grande prestador de serviços produtivos. Ou seja, além de manter níveis de concentração industrial semelhantes aos de 1985, a RMSP se converteu nesse final de século no locus das sedes de grandes empresas industriais, financeiras e prestadoras de serviço do país exatamente porque é seu pólo industrial.

Pode-se afirmar, portanto, que a RMSP, na última década passou não por um processo de "desconcentração", mas sim de reestruturação industrial. Se algumas plantas (ou par- 
te delas) foram transferidas da região, outras ali se instalaram, principalmente empresas inovadoras intensivas em ciência e tecnologia e as sedes dos conglomerados financeiros.

De fato, o que (desconcentrou e) reduziu na RMSP nesse período foi o emprego, especialmente o industrial, que demanda baixo nível de qualificação.

Da apreensão da dinâmica de transformações econômicas estruturais e seus impactos, constata-se, empiricamente, uma ruptura na trajetória histórica de evolução da economia metropolitana, mostrando pela primeira vez ausência de convergência entre a trajetória de desenvolvimento da produção e a do emprego na RMSP. Tal divergência, verificada em todas as atividades produtivas, embora com maior ênfase na atividade industrial, é visível nos indicadores de evolução do valor da produção e do pessoal ocupado, sendo característica do período em análise. Além disso, verifica-se a convergência entre a reestruturação produtiva e a concentração regional da produção industrial na RMSP, bem como seu impacto na transformação ocupacional.

Essa nova dinâmica econômica deriva da superposição de duas ordens de questões características do desenvolvimento recente da RMSP: a primeira, de natureza histórica, é fruto dos determinantes da heterogeneidade estrutural da formação econômica da região; e a segunda, sobreposta a esta, provém da natureza também heterogênea do processo de transformação em curso, que inclui e exclui empresas e pessoas do processo de produção. A natureza excludente das transformações em curso sinalizam para a tendência, em formação, de uma estrutura ocupacional polarizada, caracterizada pelas altas taxas de crescimento, em termos relativos, das ocupações em serviços auxiliares e produtivos, que contêm parcela significativa das ocupações que exigem ensino médio e superior, e, em termos absolutos, dos postos de trabalho em prestação de serviços pessoais, com baixas qualificação e remuneração.

Essa nova configuração vem se impondo à sociedade $\mathrm{e}$ provocam fortes impactos que, para serem superados, requerem a adoção de políticas econômicas e regionais ativas - para tentar "compensar" a fraca capacidade de geração de postos de trabalho característica dessa nova dinâmica econômica fortemente inibidora ao crescimento do emprego na indústria de transformação.

Portanto, a reestruturação tecnológica e as transformações estruturais aprofundaram-se, no decorrer da década de 90, no sentido da constituição de uma metrópole de serviços - e de serviços produtivos.

\section{RESULTANTES ESTRUTURAIS DAS TRANSFORMAÇÕES PRODUTIVAS}

A predominância do setor serviços em relação ao industrial deriva, de um lado, da concentração das atividades de intermediação financeira, de comunicação e de serviços prestados às empresas - serviços estratégicos, diante dos novos paradigmas da produção na RMSP -, que contribuíram tanto para a sua consolidação nacional, ${ }^{3}$ ou seja, para o nítido predomínio da região como principal centro de âmbito nacional, quanto para qualificá-la em sua inserção internacional e, de outro, da reestruturação tecnológica e das alterações nos processos de trabalho na indústria de transformação, que permanecem centrais nas trajetórias das grandes metrópoles - antigas e novas - da economia capitalista. A diversidade e o tamanho da economia e da estrutura industrial da RMSP constituíram-se nos determinantes principais de sua transformação num grande centro de serviços e negócios.

Com elevada participação em algumas das atividades mais dinâmicas da indústria de transformação nacional, o processo de reestruturação técnico-gerencial e patrimonial mostrou-se altamente disseminado no corpo da indústria metropolitana, com impactos na criação ou ampliação de serviços altamente interligados à produção industrial. De acordo com os dados da Paep (Fundação Seade, 1999), a estrutura industrial da RMSP caracteriza-se por ser:

- extremamente diversificada, uma vez que a região produz mercadorias de praticamente todas as atividades industriais. As indústrias do complexo metalmecânico (automobilística e máquinas e equipamentos), a química, a de alimentos e bebidas e a editorial, gráfica e de gravações são as cinco principais divisões (produtoras de valor) da indústria de transformação metropolitana;

- altamente heterogênea, pois está presente na estrutura industrial metropolitana uma gama multifacetada de arranjos entre tamanhos de empresas, origens de capital, grande variação de produtividade, distribuída nas várias divisões, permitindo inúmeras sínteses que cobrem um largo espectro, desde as pequenas empresas de capital nacional, que são as mais numerosas e de baixa produtividade, até as grandes empresas, de capital estrangeiro, que produzem com alta produtividade bens de capital e consumo duráveis e são responsáveis por mais de $50 \%$ do VA regional;

- muito concentrada, uma vez que na região localizam-se $57 \%$ das unidades locais industriais, com cerca de $57 \%$ 
do pessoal ocupado, produzindo $60 \%$ do valor adicionado do Estado de São Paulo. Destacam-se as principais divisões da estrutura industrial, sendo que, para as empresas das divisões intensivas em ciência, mais difusoras de inovação, os níveis de concentração são ainda maiores: estão, na RMSP, cerca de $73 \%$ das unidades locais das empresas intensivas em ciência, $65 \%$ do pessoal ocupado e cerca de $68 \%$ do valor adicionado do Estado.

O destaque do período pós-1985 é o crescimento do setor serviços, que representava $41 \%$ do VAB do Estado de São Paulo, em 1985, passando para cerca de 54\%, em 1997. A concentração da produção de serviços de informática, comunicação e educação na RMSP distingue-a no contexto nacional, capacitando-a a responder às novas e complexas demandas por informações, análises e interpretações, geradas em uma única cidade que concentra mercados e conhecimento.

O processo de terciarização da estrutura produtiva da RMSP sinaliza para a tendência de formação de mecanismos de cooperação coordenados, geralmente, por grandes empresas. Os nexos estratégicos dessas redes relacionam a estrutura industrial existente com os serviços especializados, formando arranjos horizontais entre empresas. Nesses casos, a interação entre potencialidades de natureza econômica, social e institucional, de caráter coletivo e cumulativo, é fundamental e provém da existência de uma atmosfera industrial. ${ }^{4}$ Este fenômeno, ainda incipiente no Estado de São Paulo, apresenta-se com maior intensidade na RMSP, onde a grande empresa tem forte presença na produção industrial.

Para se ter idéia da potencialidade deste processo, verifica-se que, em 1996, estavam operando na RMSP, 437 sedes de empresas industriais de grande porte (com mais de 500 pessoas ocupadas, equivalente a $61,7 \%$ do Estado de São Paulo), de alta produtividade (R $\$ 55.660,00 /$ pessoa ocupada) e distribuídas majoritariamente entre as indústrias de bens intermediários e bens de capital e de consumo duráveis (Fundação Seade, 1999). Estas empresas apresentavam os maiores índices de inovação tecnológica e de articulação da produção em redes informatizadas, indicando potenciais de integração produtiva da região. Além disso, as indústrias do complexo metalmecânico ( $27 \%$ do VA metropolitano) e aquelas intensivas em ciência (cerca de $7 \%$ do VA da região) estavam concentradas, em mais de $65 \%$ do VA estadual, na RMSP.

$\mathrm{O}$ conjunto de mudanças estruturais da RMSP reflete, no fundo, o processo de reestruturação produtiva que transformou a grande empresa fordista desse final de século em um complexo e emaranhado sistema de redes de relações entre fornecedores e distribuidores, com um núcleo central de tomada de decisões estratégicas.

Em suma, do ponto de vista produtivo, a RMSP transforma-se numa metrópole de serviços (produtivos e financeiros) sem contudo perder a dimensão de principal pólo industrial do país, onde a grande empresa industrial tem um papel central e espelha, de certa forma, as transformações em curso na região:

- ao terciarizar inúmeras atividades, criando novos serviços ligados à produção e/ou intensificando os já existentes;

- ao reduzir o pessoal ocupado, excluindo do processo de produção industrial parcela significativa dos trabalhadores que irão se deslocar, em certa medida, para ocupações no setor de serviços - de menores qualificação e remuneração e com vínculos mais precários de trabalho;

- ao inovar os processos de produção e os produtos, agregando novos métodos e técnicas, bem como criando relações mais intensas entre fornecedores e clientes, sinalizando para possibilidades de integração intersetorial no processo de produção;

- ao concentrar a produção de setores inovadores e mais dinâmicos da produção nacional e estadual - o complexo metalmecânico e as indústrias intensivas em ciência.

\section{O POTENCIAL INOVADOR DA INDÚSTRIA DE TRANSFORMAÇÃO}

Mesmo sofrendo as conseqüências dos parcos estímulos de natureza sistêmica e baixo dinamismo do início da década de 90, a economia metropolitana apresentou movimentos de reestruturação que resultaram em atividades e iniciativas inovadoras, ${ }^{5}$ mesmo que, em grande parte, de natureza incremental. ${ }^{6}$

A presença de aproximadamente $1 / 4$ das empresas industriais inovadoras - em sua maioria grandes empresas - requalifica, ao mesmo tempo em que sinaliza possibilidades de transformação da RMSP no futuro.

A atividade inovadora apresentou-se concentrada na RMSP, sendo responsável pela produção de $68 \%$ do valor adicionado industrial da região, e foi realizada em 5.918 empresas da indústria de transformação, o que representa cerca de $75 \%$ do VA das empresas inovadoras do Estado de São Paulo.

Vários são os fatores que podem explicar o desempenho inovador das empresas industriais: ${ }^{7}$ - o porte das em- 
presas - existe forte correlação entre o tamanho da empresa e sua propensão a inovar. Na RMSP, de acordo com a Paep, a proporção de empresas inovadoras cresce à medida que aumenta o tamanho: nas pequenas (de 5 a 99 pessoas ocupadas), cerca de $22 \%$ das empresas introduziram inovações; nas médias (de 100 a 499 pessoas ocupadas), a proporção sobe para 54\%; e, nas grandes (com mais de 500 pessoas ocupadas), alcança $71 \%$; - as características específicas dos setores industriais - empresas dos segmentos de bens de capital e de consumo duráveis (do complexo metalmecânico e das indústrias intensivas em ciência) e da indústria química apresentam maior desempenho inovador; - a origem do capital controlador das empresas - as de capital estrangeiro e misto (nacional e estrangeiro) têm maior desempenho inovador do que aquelas de capital nacional; - a localização das empresas verificou-se que aquelas que se encontram na RMSP apresentam maior desempenho inovador do que as do interior do Estado de São Paulo.

A estrutura industrial das empresas inovadoras na RMSP diferencia-se daquela referente ao total das empresas: é maior a participação do valor adicionado das divisões mais complexas e intensivas em tecnologia e conhecimento, pertencentes ao grupo de indústrias de bens de capital e de consumo duráveis - o complexo metalmecânico e as indústrias intensivas em ciência ( $33 \%$ do VA, para o total, e $41 \%$, para a inovadora). O tamanho da empresa também é outra característica importante de di- ferenciação: enquanto as grandes empresas da indústria de transformação eram responsáveis pela produção de $61 \%$ do VA da RMSP, as inovadoras com esse porte produziam cerca de $70 \%$ do VA da estrutura industrial inovadora da região.

Um novo papel para a RMSP deriva da importância que a região pode ter enquanto fonte geradora de estímulos e de produção de inovações e na difusão de inovações e conhecimento para o restante da estrutura produtiva nacional. Esta hipótese pôde ser aquilatada pelo fato de mais de $70 \%$ do valor adicionado das empresas inovadoras do Estado que se relacionam com as fontes de informação para inovação estar concentrado na RMSP, num contexto em que, de acordo com dados da Paep, $25 \%$ das empresas metropolitanas realizaram inovação de produto e/ou de processo no período 1994-96.

Porém, isto não significa esforço das empresas em atividades relacionadas ao desenvolvimento de $\mathrm{P} \& \mathrm{D}$, mas sim a agregação de vantagens competitivas no novo paradigma industrial. Existem fortes limitações que podem ser sintetizadas através da baixa relação observada entre as empresas industriais e as agências de produção de conhecimento científico e tecnológico enquanto fontes de informação para a inovação. Esta fraca relação constitui-se num diferencial importante da RMSP em relação aos demais centros metropolitanos, onde a concentração dos fatores de produção interagem no sentido de gerar sinergias, induzindo a produção de inovações.

TABELA 1

Empresas Inovadoras (1) e sua Proporção no Valor Adicionado da RMSP e Participação no Estado, segundo Fontes de Informação Consideradas Muito Importantes ou Cruciais para Inovação Região Metropolitana de São Paulo - 1996

\begin{tabular}{|c|c|c|c|}
\hline Fontes de Informação para Inovação & $\begin{array}{c}\text { Empresas } \\
\text { (№s Absolutos) }\end{array}$ & $\begin{array}{c}\text { Proporção no } \\
\text { VA da RMSP (\%) }\end{array}$ & $\begin{array}{c}\text { Participação do VA } \\
\text { da RMSP no ESP (\%) }\end{array}$ \\
\hline Clientes & 3.965 & 75,1 & 73,7 \\
\hline Departamento P\&D & 1.756 & 64,4 & 77,1 \\
\hline Competidores & 1.950 & 58,3 & 82,4 \\
\hline Fornecedores de Materiais & 2.625 & 49,6 & 75,6 \\
\hline Outros Departamentos & 1.004 & 40,2 & 81,0 \\
\hline Outras Empresas do Grupo & 363 & 38,6 & 85,7 \\
\hline Feiras e Exibições & 150 & 34,9 & 72,2 \\
\hline Fornecedores de Bens de Capital & 1.210 & 32,2 & 74,0 \\
\hline Publicações & 815 & 24,4 & 78,3 \\
\hline Licenças e Patentes & 639 & 23,1 & 74,7 \\
\hline Outras Fontes de Informação & 369 & 23,0 & 91,5 \\
\hline Instituto de Pesquisa & 700 & 21,3 & 74,4 \\
\hline Universidades & 539 & 17,5 & 76,7 \\
\hline Consultorias & 457 & 13,1 & 77,0 \\
\hline
\end{tabular}

Fonte: Fundação Seade. Pesquisa da Atividade Econômica Paulista - Paep.

(1) Com sede somente no Estado de São Paulo. 
O conhecimento aplicado em campos estratégicos da produção industrial, gerado nos Centros Tecnológicos e de Pesquisas das Universidades e nos Institutos de Pesquisa, é a matéria-prima essencial do processo de inovação nas principais tecnopoles do mundo. O grau de interações da RMSP é ainda limitado e a superação desse gargalo configura-se num grande desafio para seu desenvolvimento futuro.

O caráter heterogêneo da indústria metropolitana faz com que a estratégia de inovação das empresas apresente um gradiente amplo de situações. Acrescenta-se a essa característica estrutural a circunstância conjuntural negativa, pois a reestruturação das empresas industriais realizou-se em um ambiente recessivo, fazendo com que as estratégias adotadas fossem marcadas por um componente fortemente defensivo (Coutinho e Ferraz, 1994), que privilegiou inovações nos processos de trabalho com mudanças organizacionais e enxugamento do emprego derivado de ajustes nos fatores de produção.

Por outro lado, algumas empresas, principalmente as de grande porte, buscaram soluções mais flexíveis, integradoras e de aumento de produtividade via introdução de novas tecnologias, conformando soluções de caráter sistêmico.

Mesmo assim, a concentração, na região metropolitana, das empresas industriais mais inovadoras e da maior fatia da produção das indústrias intensivas em ciência contribui para a superação dos entraves existentes na região, podendo vir a transformá-la num espaço onde se concentram e interagem conhecimentos tecnológicos e científicos, instituições, empresas e mão-de-obra qualificada, diretamente no desenvolvimento da produção industrial e dos principais serviços produtivos, gerando inovações e ampliando a competitividade da região.

A dinâmica econômica derivada desta reestruturação tecnoprodutiva produz impactos com graves conseqüências para a região. Transformada, a estrutura produtiva da RMSP recria os nexos das relações intra e intersetoriais, bem como as relações inter e intra-regionais - agora com nova e mais ampla abrangência espacial. Contraditoriamente a essa perspectiva, as transformações no mercado de trabalho da RMSP acirraram as já históricas dificuldades de inclusão dos trabalhadores na estrutura ocupacional, com graves conseqüências sociais.

\section{ESTRUTURA OCUPACIONAL E POLARIZAÇÃO NO MERCADO DE TRABALHO}

As principais alterações ocorridas no mercado de trabalho da RMSP, no período 1988-99 compreendem:
- redução dos ocupados no setor industrial, que representavam cerca de $32 \%$ da estrutura ocupacional da RMSP, em 1988, passando para cerca de 20\%, em 1999;

- ampliação de ocupações no setor serviços (com destaque para os serviços relacionados à produção e os pessoais/domésticos). As ocupações do setor terciário, que respondiam por cerca de $60 \%$ da estrutura ocupacional metropolitana, em 1988, passaram para cerca de $74 \%$, em 1999.

- baixa capacidade de geração de ocupações assalariadas com carteira de trabalho assinada.

A resultante das transformações ocupacionais na RMSP, durante a década de 90 , pode ser sintetizada nos movimentos de dois segmentos do setor de serviços: produtivos/especializados, de um lado, e pessoais/domésticos, de outro.

Nos serviços relacionados à produção (ou produtivos/ especializados), expandiram-se as inserções mais flexiveis (ou não regulamentadas) no setor privado: tanto os ocupados sem carteira assinada quanto os autônomos mais que duplicaram nessa década (cerca de $250 \%$ em relação a 1988) e os empresários e donos de pequenos negócios familiares aumentaram em mais de $130 \%$. Alguns desses serviços - estratégicos para a nova organização das empresas - agregam segmentos novos, provedores da informação e dos meios essenciais para aumentar a produtividade das empresas. Nestas atividades do setor serviços estão mais concentradas as ocupações que exigem nível superior de escolaridade. Essa qualificação corresponde a apenas 7\% dos ocupados em serviços na RMSP, $3 \%$ na indústria, $1 \%$ no comércio e $5 \%$ na construção civil. O desempenho desse grupo de ocupações, aparentemente, decorre da terceirização de parcela das atividades e/ou das novas demandas forjadas pelas mudanças tecnogerenciais da indústria de transformação metropolitana, que têm requerido novas atividades de serviços especializados, inclusive de nível superior. Verificou-se a existência de vários serviços demandados pelas indústrias - realizados no interior das empresas ou contratados fora - que envolvem ocupações desse nível de qualificação.

Nos serviços pessoais também aumentaram as inserções mais flexíveis (ou não regulamentadas) no setor privado: tanto os ocupados sem carteira assinada quanto os autônomos que trabalham para empresa mais que duplicaram nessa década, muito embora apenas neste segmento tenha crescido o emprego assalariado com carteira assinada. Nos serviços pessoais, as ocupações requerem, em grande par- 
te, nível de escolaridade básico ou inferior. Destacam-se os serviços domésticos que, em 1999, representavam cerca de $9 \%$ da PEA metropolitana, encabeçando a lista das ocupações que mais cresceram nessa década - com incremento de aproximadamente 48\% desde 1988 .

Cabe salientar a predominância, na RMSP (como também na Região Metropolitana do Rio de Janeiro - as duas maiores áreas metropolitanas do Brasil), de ocupações de nível básico, sem qualificação, com as menores remunerações e crescente precarização da posição na ocupação. Em termos absolutos, as ocupações que mais cresceram nessas duas regiões são: serviço doméstico, vigilância privada, atendente de serviços, atendente balconista, motorista, entre outras. Por outro lado, as ocupações que mais diminuíram na RMSP pertencem à indústria de transformação e resultam do impacto da introdução das novas tecnologias nos processos de trabalho dos diversos setores industriais.

Na RMSP, a exemplo do que aconteceu em outros países industrializados, as transformações na estrutura ocupacional ocorrem com a manutenção de uma estrutura produtiva densamente industrial: a indústria continuava a representar, em 1999, 1/4 dos empregos da região.

A relação entre a proporção de empregos em serviços e na indústria de transformação, na RMSP, cresceu abaixo daquela verificada para a PEA urbana do Brasil e das demais regiões metropolitanas. Observou-se, para as outras regiões metropolitanas brasileiras e para alguns países desenvolvidos, um movimento geral de terciarização das estruturas ocupacionais, com defasagens temporais determinadas, entre outros aspectos, pelos períodos em que se processaram as reestruturações tecnológicas nas diferentes regiões/países. No Brasil e nas suas regiões metropolitanas, os movimentos de terciarização surgiram com maior intensidade na década de 90 .

\section{IMPACTOS SOCIAIS DA REESTRUTURAÇÃO PRODUTIVA}

A dinâmica econômica derivada desta reestruturação tecnoprodutiva produz impactos sociais com graves implicações para a RMSP. Associada à péssima distribuição de renda do país, a deterioração das condições de acesso ao mercado de trabalho mostrou-se mais desfavorável aos mais pobres.

São inúmeros os determinantes da situação de carência social na RMSP: desde as condições históricas de reprodução da pobreza e da exclusão social, até o descaso das políticas públicas pela melhoria das condições de vida da população, assim como a restrita incorporação de pessoas ao mercado de trabalho em condições não-precárias de emprego e renda.

No final da década de 90 , cresceram as dificuldades devido à queda do nível da atividade econômica, repercutindo diretamente nos estratos mais pobres da população, em especial daquela residente nas regiões metropolitanas. A proporção dos pobres na RMSP apresentou trajetória acelerada de crescimento: evoluiu de aproximadamente $27 \%$, em 1995, para $30 \%$, em 1997, chegando próximo a $39 \%$, em 1999 , um aumento de $45 \%$ em apenas quatro anos.

Tem-se a formação, segundo Rocha (2000), de "um amplo contingente de pobres estruturais, dentre os quais se incluem - em função dos baixos rendimentos na base da distribuição - mesmo aqueles que participam normalmente no mercado de trabalho". A autora exemplifica esta situação com a RMSP, onde, com o salário mínimo de $\mathrm{R} \$ 151,00$ e a linha de pobreza per capita mensal estimada para a região na ordem de $\mathrm{R} \$ 167,00$ (set. 1999), um indivíduo que receba dois salários mínimos e tenha um filho estará situado abaixo da linha de pobreza.

Enquanto a proporção dos pobres metropolitanos cresce nessa velocidade, no Nordeste rural, por exemplo, a pobreza apresenta leve redução e no total da população rural brasileira mantém-se estabilizada em torno de $34 \%$, nesse mesmo período (Rocha, 2000:anexo 2). Diferentemente do passado recente, o crescimento do número de pobres ocorre no coração econômico do país - na RMSP - e, como sempre, está associado à falta de emprego e de boas oportunidades de inserção no mercado de trabalho. Ou seja, o crescimento da pobreza na RMSP não é mais resultado da "urbanização da pobreza rural" a que se referia Rangel (2000), nos anos 70 e 80, mas sim uma conseqüência da própria reestruturação produtiva ocorrida na região nos anos 90 .

Soma-se a essas condições a postura defensiva adotada pelas empresas em suas decisões de investimentos, que, de acordo com Coutinho (1996:60), leva a dois riscos:

- desagregação social das áreas metropolitanas, causada pela concentração de "efeitos perversos (...) com a crise do velho padrão industrial; convivência restrita com novas funções e atividades de elevada qualificação e renda; rescaldo da mobilidade descendente, decorrente das atividades industriais e funções obsoletizadas pela mudança tecnológica; e 
- exclusão de áreas periféricas, não dotadas de infra-estrutura e de população com grau satisfatório de educação, tornando renitentes os bolsões de miséria em função da dificuldade de articular 'externalidades' positivas para atração de investimentos".

A RMSP apresenta características dessa ordem, pois, do ponto de vista urbano, é composta por espaços muito diferenciados e conflituosos: reúne, no seu interior, municípios pobres ou mesmo miseráveis - dormitórios de trabalhadores pobres com famílias carentes e, pior, administrados por prefeituras igualmente pobres e carentes, sujeitas às condições de regressividade do sistema tributário vigente no país - e municípios ricos, os mais industrializados do país, com rendas per capita que se assemelham aos padrões dos países desenvolvidos, administrados por prefeituras igualmente bem posicionadas em face das demais.

Em ambos os casos, as administrações encontram-se impotentes para solucionar problemas da envergadura dos que se apresentam com as mutações em curso no aparato produtivo da região.

Como se observou, o desenvolvimento da RMSP, nas últimas décadas, parece resultar dessa desarticulação das relações entre determinantes políticos, econômicos e territoriais. As ações nessas esferas nem sempre são convergentes, o que imprime à região uma trajetória e uma resultante que parecem difusas, pois a complexidade aprofunda-se e o grau de dispersão de possibilidades potencializa-se - com graves conseqüências para o futuro.

\section{IMPACTOS ESPACIAIS DA REESTRUTURAÇÃO PRODUTIVA}

A dinâmica territorial derivada da reestruturação tecnológica vem se caracterizando por um profundo movimento de reconcentração-desconcentração produtiva a partir da Região Metropolitana de São Paulo e está associada à indústria e aos serviços de suporte estratégico ao processo de produção e à gestão empresarial.

No Estado de São Paulo, os efeitos da reestruturação produtiva produziram dinâmicas espaciais realimentadoras de processos de concentração, aprofundando os nexos econômicos entre a RMSP e seu entorno.

As principais regiões industrializadas do Estado de São Paulo (com exceção das agroindustriais e do couro) e as densamente urbanizadas - formando áreas metropolitanas, como Campinas, ou grandes aglomerações urbanas, como São José dos Campos - intensificaram sua produção in- dustrial nas duas últimas décadas e passaram a se relacionar com a RMSP através de intercâmbios rotineiros de produção e trabalho.

Esta ampla região, interligada por redes de autopistas e de cabos de fibra ótica (em quase toda sua extensão), possui o maior complexo de produção de ciência e tecnologia do país, concentrando quase toda a produção das empresas intensivas em ciência do Estado (96\% do VA, segundo a Paep 1996).

Ao serem agregadas à RMSP as iniciativas de investimento das empresas em novas plantas industriais captadas pela Paep nas regiões de Campinas, São José dos Campos, Sorocaba e Santos, fica evidente o caráter concentrador das ações empresariais no espaço estadual.

As unidades locais novas, instaladas no período 199096, seja em número de unidades ( $78 \%$ das ULs), seja em valor adicionado ( $90 \%$ do VA), encontram-se, em maior proporção, nessas regiões.

Entre 1994 e 1996, cerca de 3.062 unidades locais situadas no entorno metropolitano ampliaram a capacidade produtiva, representando cerca de $27 \%$ das unidades que afirmaram à Paep ter realizado tal investimento no Estado. Somadas às da RMSP, elas representam cerca de $80 \%$ desse universo.

A estrutura industrial do conjunto das regiões que configuram o entorno da RMSP apresenta elevado grau de integração técnica e funcional com esta. Pode-se afirmar que, nessa porção do território paulista, encontra-se em curso um extenso processo de metropolização, integrando aglomerações urbanas metropolitanas (São Paulo, Campinas e Santos) e não-metropolitanas (São José dos Campos e Sorocaba) em uma grande área socioeconômica.

\section{IMPLICAÇÕES DERIVADAS DA REESTRUTURAÇÃO PRODUTIVA}

A transformação estrutural ocorrida na RMSP no final do século XX tem implicações contraditórias para a gestão metropolitana. A reestruturação tecnoprodutiva acarretou mudanças no papel estratégico que a região passou a assumir.

A RMSP adquire - pelo alto grau de concentração das atividades relacionadas à gestão e ao comando empresarial, financeiro e produtivo-tecnológico - condições para difundir, para o restante dos centros urbanos e metrópoles nacionais, os novos paradigmas produtivos e as decisões econômicas, financeiras e empresariais engendradas a partir dela. Além disso, adquire condições para articu- 
lar interesses internos e externos no sentido de galgar posições superiores em seu desenvolvimento econômico e social.

Como decorrência dessas transformações, impõe-se uma nova agenda para a gestão pública e para o planejamento regional, tendo em vista o complexo desafio imposto à RMSP: ter que ser, a um só tempo, competitiva $\mathrm{e}$ integradora. ${ }^{8}$

As transformações estruturais em curso vêm agregando à RMSP melhores condições de competitividade. Nela, o novo paradigma da produção industrial parece, em alguma medida, estar se realizando, ao menos no âmbito das grandes empresas, onde se concentram as atividades inovadoras, a utilização de redes entre clientes e fornecedores e as tecnologias de informação e de comunicação.

A transformação estrutural da região metropolitana e a reestruturação tecnoprodutiva convergem no sentido de requalificar a natureza da polarização exercida pela região. A transformação estrutural direcionada ao setor serviços significou, por um lado, a concentração de atividades cada vez mais articuladas com os fluxos comerciais, financeiros, tecnológicos e de informação e, por outro, a ruptura da dinâmica do mercado de trabalho.

A densidade de fluxos de decisão, de conhecimento e de informação faz com que, na RMSP, localizem-se as principais empresas do país. A possibilidade de serem desenvolvidas redes complexas de relações produtivas e comerciais determina, em última instância, a competitividade da região, ao mesmo tempo em que amplia sua centralidade neste novo estágio do desenvolvimento capitalista. A RMSP passa a ser alvo do interesse nacional (e internacional) e, ao mesmo tempo, sua sustentabilidade deve provir de articulações público-privada.

Outro grande desafio que as transformações estruturais colocam para a RMSP é o de ser integradora, ou seja, de se constituir no local onde os pontos-chave do processo de produção e de comando realizam-se e onde os setores intermediários da economia e a população urbana operam o seu cotidiano.

Esta é a grande questão a ser enfrentada pela gestão metropolitana. Se, por um lado, a RMSP transforma-se em local estratégico à gestão das atividades financeiras, comerciais e de produção industrial de âmbito nacional e de importância internacional - tal como as grandes aglomerações urbanas mundiais, particularmente as de caráter metropolitano -, por outro, necessita ser capaz de integrar a população no cotidiano da produção.
Traço fundamental de diferenciação entre a RMSP e as metrópoles das economias desenvolvidas encontrase na trajetória contraditória e na ampliação da heterogeneidade, com sinais que implicariam um processo de polarização da estrutura ocupacional regional qualitativamente diverso daquelas. Na RMSP, a trajetória de ampliação das ocupações no setor serviços tende a se dar em duas extremidades (serviços ligados à produção/especializados, em uma ponta, e serviços pessoais sem qualificação/emprego doméstico, na outra), assim como no crescimento relativo do assalariamento nas ocupações mais tradicionais e na precarização das relações de trabalho nos segmentos de serviços vinculados ao processo mais dinâmico de produção. A rapidez com que a desregulamentação das relações de trabalho nos segmentos mais dinâmicos do setor serviços tem acontecido na RMSP sinaliza para a necessidade, urgente, de novas formas de regulação, em substituição ao laissez faire vigente, ou à predominância do livre jogo do mercado. Isto porque, se for considerada a hipótese de que esta mudança é derivada, em grande medida, do processo de reestruturação tecnológica e que sua transformação tem caráter estrutural, estar-se-á diante de questões de alto significado para o desenvolvimento futuro da sociabilidade e da natureza integradora da RMSP.

Essas questões remetem a impactos de natureza cultural e antropológica acerca do significado do trabalho e da sua representação simbólica para o desenvolvimento dos indivíduos e das relações sociais, inclusive familiares. As noções de futuro, de segurança e de projeto de vida entram em uma zona cinzenta, em que a desintegração e a desarticulação de laços afetivos e sociais tendem a crescer e as certezas encontram-se abaladas, prevalecendo a insegurança.

O impacto desta apreensão no cotidiano da população pode significar a fragilização de valores, até então essenciais nas estratégias de sobrevivência da maioria da população metropolitana - tais como a solidariedade e a cooperação.

A insegurança sobre o presente e o futuro tem outros componentes, como, por exemplo, a violência urbana, a baixa qualidade e o difícil acesso aos serviços sociais, a falta de garantia de inserção dos jovens e dos "excluídos" ao mundo do trabalho, etc., que possibilitam a potencialização de conflitos urbanos, sociais e entre indivíduos e classes sociais na RMSP.

Enfim, a definição de novas regras para as relações entre os sujeitos do mundo do trabalho parece essencial para 
se gerar nova sociabilidade com graus crescentes de solidariedade, participação e cidadania.

Da mesma forma, um tecido produtivo baseado em cooperação, conhecimento e inovação deve ser incentivado, visando ampliar a competitividade e a atratividade da região.

Como contraposição às tendências assinaladas, também é indispensável a definição de novos formatos institucionais de gestão pública para a RMSP, construindo-se novos parâmetros para o desenvolvimento futuro da grande metrópole brasileira - a RMSP.

Em síntese, o que é mais significativo e resultante das transformações estruturais da RMSP corresponde ao seu papel polarizador na produção e na oferta dos serviços produtivos modernos do país, à situação enquanto centro do sistema financeiro nacional e sede dos principais grupos e grandes empresas nacionais e estrangeiras, bem como à sua permanência como principal pólo industrial do país.

Assim, está colocado o debate acerca das contradições e dos novos ingredientes que, a partir das transformações estruturais e da reestruturação tecnoprodutiva, incorporaram-se de forma definitiva ao desenvolvimento da RMSP, conferindo-lhe uma nova centralidade.

Talvez uma metáfora ajude no entendimento do que se pode denominar "a nova centralidade" da Região Metropolitana de São Paulo.

Antes, a RMSP era conhecida como o "coração do país", porque aqui se concentrava a maior parte da sua produção industrial que, ao demandar matérias-primas e fornecer insumos e produtos finais, irrigava as economias de outras regiões através das estradas e ferrovias que partiam da metrópole paulista. Hoje, o coração permanece pulsante e irrigando economias das mais distantes regiões do país através dessas mesmas artérias cada vez mais entupidas, antecipando um colapso iminente.

Porém, agora são as decisões tomadas nas sedes das grandes empresas industriais e financeiras localizadas na RMSP que movimentam as demais economias regionais. É nas sedes dessas grandes empresas que se tomam as decisões fundamentais de investir ou não, transferir plantas ou parte delas, desativar linhas de produção, inovar, etc. e que trafegam através de infovias que conectam redes informatizadas de transmissão de dados.

Literalmente, e para concluir, pode-se dizer que a RMSP tornou-se a cabeça de um novo e complexo sistema de relações produtivas e financeiras assentado nas grandes empresas e suas redes de fornecedores e distribuidores, que aqui têm os seus centros "pensantes" de decisão.

\section{NOTAS}

E-mail da autora: fatima@seade.gov.br

Este artigo é um resumo do capítulo de conclusões da tese de doutoramento da autora (Araujo, 2001), defendida junto ao Instituto de Economia da Unicamp, sob a orientação do Prof. Dr. José Graziano da Silva. Agradeço a Vagner Bessa a leitura atenta da versão anterior deste texto.

1. Recente estudo realizado sobre a nova configuração da rede urbana brasileira localiza a RMSP no topo da hierarquia urbana brasileira, qualificando sua centralidade. Ver: Ipea/IBGE/Unicamp (1999).

2. Para uma síntese histórica da formação da RMSP, ver: Araujo (1992a:17-51); Araujo e Pacheco (1992:55-92).

3. Segundo Sassen (1998 e 1999), a expressão "consolidação nacional” significa o processo em que um centro urbano ou metropolitano passa a prevalecer sobre outros do mesmo país de forma inequívoca. A autora utiliza essa expressão para qualificar a supremacia de um centro financeiro sobre outros em um determinado país, ex: Londres, Nova Iorque, São Paulo, entre outros.

4. Segundo Benko e Lipietz (1992) “(...) para estar em el centro de la información no es suficiente consultar un terminal de ordenador, es necesario estar allí donde estan los demás, es preciso comer juntos, intercambiar o sonsocar confidencias, es decir, bañarse en una atmósfera, la palavra clave de la concepción marshalliana del distrito. La telemática no há suplantado aún el cara a cara." Ver também, a esse respeito, Diniz e Gonçalves (2000).

5. O conceito de empresa inovadora aqui utilizado, tal como na Paep, acompanha a metodologia de estudo sobre inovação tecnológica adotada pela Organização para Cooperação e Desenvolvimento Econômico (OCDE). A Paep considerou inovadora a empresa que, no período de 1994 a 1996, desenvolveu algum tipo de transformação tecnológica, seja nos produtos, seja nos processos de produção. A inovação de produto pode estar relacionada à elaboração de um produto com características inteiramente novas (inovação significativa) ou a ligeiras modificações realizadas em produto já existente (inovação incremental). Por sua vez, a inovação de processos corresponde à adoção de uma nova forma de produzir que, efetivamente, promova mudanças no desenvolvimento do processo produtivo, através da introdução e uso de máquinas e equipamentos mais automatizados e/ ou de novos métodos de organização do trabalho.

6. Entende-se por inovação de natureza incremental o substancial aperfeiçoamento tecnológico de produto previamente existente. Um produto tecnologicamente aperfeiçoado é um produto preexistente, cuja performance tenha sido substancialmente melhorada ou avançada. Um produto simples pode ser aperfeiçoado (em termos de melhor desempenho ou custo menor) através do uso de componentes ou matérias-primas de melhor desempenho, enquanto um produto complexo, que consiste na integração de um número de subsistemas técnicos, pode ser aperfeiçoado através de mudanças parciais em um dos subsistemas.

7. Ver análise sobre o "Desempenho Inovador da Indústria Paulista" em Quadros et alii (2001).

8. A respeito da necessidade de superação da contradição entre competitividade econômica e integração social como requisito para melhorar a qualidade de vida nas cidades globais, ver Borja e Castells (1996).

\section{REFERÊNCIAS BIBLIOGRÁFICAS}

ARAUJO, M. de F.I. "Os cem últimos anos na história da cidade e a formação da Grande São Paulo". In: CANO, W. (coord.). São Paulo no Limiar do Século XXI: cenários da urbanização paulista $-A$ região administrativa da Grande São Paulo. São Paulo, Fundação Seade, v.6, 1992a.

"Uma nova centralidade da Região Metropolitana de São Paulo". São Paulo em Perspectiva. São Paulo, Fundação Seade, v.6, n.3, 1992b, p.55-59.

"Mapa da estrutura industrial e comercial no Estado de São Paulo". São Paulo em Perspectiva. São Paulo, Fundação Seade, v.13, n.1-2, 1999, p.40-52.

. Impactos da reestruturação produtiva sobre a Região Metropolitana de São Paulo no final do século XX. Tese de Doutorado. Campinas, IE/Unicamp, maio 2001.

ARAUJO, M. de F.I.; DINIZ FILHO, L.L. e BESSA, V. de C. "O terciário metropolitano". In: CANO, W. (coord.). Op. cit., 1992, p.95-142. 
"Principais alterações no espaço urbano da metrópole entre 197089”. In: CANO, W. (coord.). Op. cit., 1992, p.145-182.

ARAUJO, M. de F.I. e PACHECO, C.A. "A trajetória econômica e demográfica da metrópole nas décadas de 70-80”. In: CANO, W. (coord.). Op. cit., 1992, p.55-92.

BENKO, G. e LIPIETZ, A. (orgs.). Les régions qui gagnent - districts et réseaux: les nouveaux paradigmes de la géographie économique. Paris, Presses Universitaires de France, 1992.

BORJA, J. e CASTELLS, M. The local and the global: cities in the information age. ONU/Habitat Center. Habitat II - The city summit. Istambul, 1996.

CASTELlS, M. A sociedade em rede. São Paulo, Paz e Terra, 1999.

CASTELLS, M. e HALL, P. Tecnopolis del mundo: la formación de los complejos industriales del siglo XXI. Madri, Alianza Editorial, 1994.

COUTINHO, L. “A fragilidade do Brasil em face da globalização". In: BAUMANN, R. (org.). O Brasil e a economia global. Rio de Janeiro, Campus Sobeet, 1996

COUTINHO, L. e FERRAZ, J.C. (orgs.). Estudo da competitividade da indústria brasileira. São Paulo, Papyrus, 1994.

DINIZ, C.C. e GONÇALVES, E. "Possibilidades e tendências locacionais da indústria do conhecimento do Brasil." XXVIII Encontro Nacional de Economia. Anais... Campinas, 2000.

FLEURY, A. e FLEURY, M.T.L. Estratégias empresariais e formação de competências: um quebra-cabeça caleidoscópico da indústria brasileira. São Paulo, Atlas, 2000.

FUNDAÇÃO SEADE. Pesquisa da Atividade Econômica Paulista-Paep 1996. São Paulo, 1999.

IPEA/IBGE/UNICAMP - Instituto de Pesquisa Econômica Aplicada; Instituto Brasileiro de Geografia e Estatística; Universidade Estadual de Campinas. $\mathrm{Ca}$ - racterização e tendências da rede urbana do Brasil. Campinas, Editora da Unicamp/Instituto de Economia, 2 v., 1999 (Coleção Pesquisas, 3).

LAPLANE, M. F. e SARTI, F. "Investimento direto estrangeiro e a retomada do crescimento sustentado nos anos 90". Economia e Sociedade. Campinas, n.8, jun. 1997, p.143-181.

MONTAGNER, P.; BERNARDES, R.C. e MATTEO, M. "A demanda por serviços: o que há de novo na economia paulista". São Paulo em Perspectiva. São Paulo, Fundação Seade, v.13, n.1-2, jan.-jun. 1999.

PACHECO, C.A. "A terciarização dos 80: de tudo um pouco". São Paulo em Perspectiva. São Paulo, Fundação Seade, v.6, n.3, jul.-set. 1992, p.27-38.

A fragmentação da nação. Tese de Doutorado. Campinas, Instituto de Economia/Unicamp, 1998.

QUADROS, R. et alii. "Padrões de inovação tecnológica na indústria paulista: comparação com os países industrializados”. São Paulo em Perspectiva. São Paulo, Fundação Seade, v.13, n.1-2, jan/jun. 1999.

"Inovação tecnológica e tecnologia da informação na indústria paulista". Projeto indicadores de ciência, tecnologia e inovação do Estado de São Paulo. S.1., 2001, mimeo.

RANGEL, I.M. Crise agrária, industrialização e crise urbana no Brasil. Porto Alegre, Editora UFRS, 2000.

ROCHA, S. Pobreza no Brasil. O que há de novo no limiar do século XXI? S.1., set. 2000 , mimeo.

SASSEN, S. As cidades na economia mundial. São Paulo, Studio Nobel, 1998. $08 / 01 / 99$

"Os centros financeiros globais". Gazeta Mercantil. São Paulo,

SCOTT, A.J. "L'économie métropolitaine: organization industrielle et croissance urbaine”. In: BENKO, G. e LIPIETZ, A. (orgs.). Op. cit., 1992. 